\title{
Peran Majelis Taklim Al-Hidayah dalam Pendidikan Islam dan Gerakan Sosial Keagamaan di Propinsi Lampung
}

\author{
Rumadani Sagala \\ Universitan Islam Negeri Raden Intan Lampung, Lampung \\ E-mail : rumadani@radenintan.ac.id
}

\begin{abstract}
The era of globalization of life has been integrated with the cyber world with the need to foster religious life, one of which is conducting non-formal education such as the Majlis ta'lim which has been investigated lately. Lampung province for Islamic education and socio-religious movements. Specifically, this research plan will raise the role, role, strategy of institutional development by taking studies at the Majelis Taklim Al-Hidayah Bandar Lampung, East Lampung, Central Lampung, and Pesawaran. The method of this research is a qualitative approach by providing a qualitative description of the role of the Al-Hidayah clerics in Islamic education and socio-religious movements. The results of this study that the existence of the Lampung province's Al-Hidayah study during the research process was carried out since mid-2018, demonstrating its role, duties and functions as non-formal educational institutions that engaged in women's groups in order to strengthen maternal capacity and knowledge especially in Islamic education religious social movements.
\end{abstract}

Keywords: Religious Social Movements; Majelis Taklim Al-Hidayab; Islamic Education

\section{Pendahuluan}

Islam sebagai agama rahmat memberi peluang kepada manusia untuk mengembangkan diri berdasarkan al-Quran dan hadis, pengembangan diri berdasarkan wahyu merupakan cita-cita al-Quran. ${ }^{123}$ Saat ini perkembangan masyarakat dunia dari waktu ke waktu terus berubah, mau tidak mau dipaksa untuk ikut dalam perubahan dunia. ${ }^{4}$

Revolusi industri 4.0 memberikan kebebasan kepada manusia dalam mengakses informasi, ${ }^{5789}$ di mana kehidupan telah terintegrasi dalam dunia cyber, yang diseragamkan oleh produk budaya global dan secara bersamaan menjadi budaya populer baru, ${ }^{10}$ di sinilah letak pentingnya pendidikan islam dan gerakan sosial keagamaan dalam rangka adaptasi

${ }^{1}$ Robiatul Awwaliyah and Hasan Baharun, 'Pendidikan Islam Dalam Sistem Pendidikan Nasional', Jurnal Ilmiah DID AKTIKA, 19.1 (2018), 37.

${ }^{2}$ Handieni Fajrianty And Ressi Susanti, 'Strategi Pembinaan Dakwah Syarhil Quran Di Padepokan Syarhil Quran Lampung', Jurnal Aqlam, 2.2 (2017), 130.

${ }^{3}$ Sukring Sukring, 'Pendidik Dalam Pengembangan Kecerdasan Peserta Didik (Analisis Perspektif Pendidikan Islam )', Tadris: Jurnal Keguruan Dan Ilmu Tarbiyah, 01.1 (2016), 69.

${ }_{4}^{4}$ Akmal Hawi, 'Tantangan Lembaga Pendidikan Islam', Tadrib, 3.1 (2017), 144.

${ }^{5}$ Farida Ariyani And Others, 'Development Of Photonovela With Character Education: As An Alternative Of Physics Learning Media', Jurnal Ilmiah Pendidikan Fisika Al-Biruni, 07.October (2018), 228.

${ }^{6}$ S Buer And Others, 'Industri 4.0 And Lean Manufacturing: Mapping Current Research And Establishing A Research Agenda', International Journal Of Production Research, 56.8 (2018), 2924.

7 Sigit Priatmoko, 'Memperkuat Eksistensi Pendidikan Islam Di Era 4.0', Ta'lim:Jurnal Studi Pendidikan Islam, 1.2 (2018), 2.

8 Agung Suprapto, 'Analisis Dimensi Kebutuhan Pra Implementasi E-Learning Untuk Meningkatkan Mutu Layanan Pendidikan Kampus Di Era Revolusi Industri 4 . 0’, Attarbiyah, 28 (2018), 81.

9 Wahyudi Setiawan and others, 'Pendidikan Kebahagiaan Dalam Revolusi Industri 4', $A L$ MURABBI: Jurnal Studi Kependidikan Dan Keislaman, 5.1 (2018), 102.

10 Samsul Munir, 'Politik Pendidikan Islam Berbasis Multikultural: Konsep Dan Strategi Pembelajaran Agama Islam Dalam Mewujudkan Islam Rahmatan Li Al- ‘ Ā Lam İ N’, Dirosat, 2.2 (2017), 155. 
dengan situasi sosial masyarakat yang kompleks. ${ }^{1112}$ Pendidikan seharusnya memberikan kesadaran dan pemberdayaan. ${ }^{13}$ Teori sosial lebih banyak dipakai karena lebih sesuai dengan alam demokrasi dan tuntutan hak-hak asasi manusia yang, ${ }^{14}$ berfungsi sebagai sarana pendidikan dalam membentuk perilaku sosial, dengan melakukan gerakan sosial inilah diharapkan akan mampu memberikan kontribusi nyata dalam pembangunan hidup beragama, ${ }^{15}$ tidak hanya pada pendidikan islamnya namun dalam konteks kehidupan sosialreligius masyarakatnya juga. ${ }^{16}$

Pembinaan hidup beragama tidak dapat diabaikan guna mewujudkan generasi agar memperkuat mental spiritual, membentuk karakter, dan iman yang kuat, bentuk pembinaan tersebut tidak mesti bersifat formal melainkan juga non formal seperti pengajian- pengajian dan majelis ta'lim. ${ }^{171819}$ Majelis Ta'lim sebagai sebuah sistem pendidikan Islam nonformal tertua di Indonesia, hal ini dikarenakan Majelis Ta'lim selain sebagai sarana pendidikan, ia dijadikan pula sebagai media dakwah yang cukup efektif, sehingga keberadaan Majelis Ta'lim tidak dapat terlepas dengan unsur-unsur dakwah Islam yang sudah dimulai sejak diutusnya Nabi Muhammad saw. ${ }^{202122}$

Tujuan pendidikan agama Islam secara umum tidaklah lepas dari tujuan hidup manusia menurut syariat Islam, yaitu mengabdi kepada Allah untuk mencapai kebahagian hidup di dunia dan di akhirat. ${ }^{232425}$ Kemudian melakukan proses pendidikan masyarakat sekaligus sebagai modal sosial yang terus diberikan penguatan dan penghargaan untuk

${ }^{11}$ Muliaty Amin, A Marjuni, And Dewi Azharia, 'Gerakan Sosial Keagamaan Masyarakat Perspektif Pendidikan Islam: Majelis Taklim Al-Mu’minat’, Jurnal Aqidah-Ta, 4.2 (2018), 150.

12 Syamsul Kurniawan, 'Pendidikan Karakter Dalam Islam Pemikiran Al-Ghazali Tentang Pendidikan Karakter Anak Berbasis Akhlaq Al-Karimah', Tadrib, 3.2 (2017), 199.

13 Samsudin, 'Integrasi Tri Pusat Pendidikan Dalam Pendidikan Agama Islam', Al-Murabbi: Jurnal Studi Kependidikan Dan Keislaman, 5.2 (2019), 218.

14 Sugeng Kurniawan, 'Peranan Kepemimpinan Visioner Dalam Manajemen Pendidikan Anak Usia Dini ( Paud )', Nur El-Islam, 5.1 (2018), 43.

15 Rihlatul Khoiriyah And Others, 'Penguatan Kampung Santri Untuk Pengembangan Masyarakat Sadar Hukum Di Wilayah Mangkang Kota Semarang', Dimas, 17.2 (2017), 255.

16 Ahmad Anas And Hendri Hermawan Adinugraha, 'Naqsyabandiyah Di Grobogan', Jurnal Komunikasi Islam, 08.01 (2018), 181.

17 Abdullah, 'Komplementaritas Dakwah Kultural Dan Struktural', Jurnal Pengembangan Masyarakat, 4.4 (2017), 2.

18 Ahmad Marzuki, 'Dinamika Dan Peran Majelis Ta'lim Dalam Meningkatkan Pengetahuan Keagamaan Di Wilayah Suku Tengger', Jurnal Mafhum, 1.2 (2016), 186.

${ }_{19}$ Muhamad Arif Mustofa, 'Majelis Ta'lim Sebagai Alternatif Pusat Pendidikan Islam (Studi Kasus Pada Majelis Ta'lim Se Kecamatan Natar Lampung Selatan) Muhamad', Jurnal Kajian Keislaman Dan Kemasyarakatan, 1.01 (2016), 5.

20 Zaini Dahlan, 'Kebijakan Pemerintah Orde Baru Terhadap Majelis Ta' Lim', Al-Fatib: Jurnal Pendidikan Dan Keislaman, 1.1 (2018), 125.

${ }^{21}$ Nyayu Khodijah, 'Majelis Taklim Asy Syifa: Potret Majelis Taklim Dalam Komunitas Muslim Muallaf Di Bali', Ri'ayah, 3.2 (2018), 85.

${ }^{22}$ Agus Sarifudin Rini Widi Astuti, M Priyatna, 'Pengaruh Majelis Taklim Ibu-Ibu Terhadap Minat Mendalami Agama Islam’, Prosiding Al Hidayah Pendidikan Agama Islam, 1.1 (2018), 139.

23 İbrahim Aşlamacı And Recep Kaymakcan, 'A Model For Islamic Education From Turkey : The Imam-Hatip Schools’, 39.7 (2016), 1 <Https://Doi.Org/10.1080/01416200.2015.1128390>.Asla

${ }^{24}$ A. Saiful Aziz, 'Pendidikan Agama Pada Anak Mucikari Di Lokalisasi Gambilangu Mangkang Semarang', 2016, 2

25 Siti Maryam, 'Pendidikan Agama Islam Dalam Persepektif Al Quran ( Studi Analisis Dalam Memahami Konsep Pendidikan Yang Ada Dalam Al Qur' An )', At-Ta'lim, 5.1 (2019), 81. 
melakukan transformasi dalam membentuk manusia seutuhnya. ${ }^{2627}$ Banyak majelis taklim di Indonesia beberapa diantanya; majelis taklim Nurul Hidayah, ${ }^{28}$ Majelis taklim $\mathrm{Al}$ Muhajirin. ${ }^{29}$ Dalam hal ini peneliti akan melihat peran majelis taklim Al-Hidayah pada pendidikan islam dan gerakan sosial keagamaan di Lampung.

Pengajian Al-Hidayah merupakan satu dari sekian banyak lembaga majelis taklim yang bergerak dalam pengajian keagamaan di Indonesia yang berbasiskan kaum perempuan. Semua jamaah dan pengurus pengajian Al-Hidayah, baik di pusat maupun di daerah, adalah kaum perempuan, terutama ibu-ibu rumah tangga. Pengajian ibu-ibu yang digerakkan oleh kelompok majelis taklim ini cukup berhasil mengajak kaum perempuan berpartisipasi aktif di luar rumah melalui kegiatan pengaiian keagamaan dan kegiatan sosial. Oleh karena itu, tak jarang ada yang beranggapan bahwa majelis taklim identik dengan pengajian ibu-ibu. Bahkan dalam sebuah buku yang mengidentifikasi peran ulama perempuan Indonesia, keberadaan majelis taklim perempuan banyak memunculkan ulama-ulama perempuan Indonesia. ${ }^{30}$

Penelitian sebelumnya telah membahas mengenai peran majelis taklim diantaranya pengaruh majelis taklim terhadap solidaritas sosial mekanik jamaah majelis taklim masjid albarokah, pengok kec. gondokusuman yogyakarta, ${ }^{31}$ pendidikan non formal berbasis masjid sebagai bentuk tanggung jawab umat dalam perspektif pendidikan seumur hidup. ${ }^{32}$ Beda penelitian ini dari penelitian sebelumnya yaitu peneliti akan menyajikan peran majelin taklim Al-Hidayah dalam pendidikan islam dan gerakan sosisal keagamaan di Bandar Lampung, Lampung Timur, Lampung Tengah, dan Pesawaran.

Terdapat beberapa alasan mengapa empat wilayah itu yang dipilih sebagai lokasi penelitian ini, dari semua Majelis Taklim Al-Hidayah yang ada di propinsi Lampung, keempat wilayah itu terhitung yang paling aktif menyelenggarakan kegiatan dakwah, sosial, kesehatan dan pendidikan, sehingga keempatnya dipilih sebagai sampel penelitian ini terkait tema pendidikan dan gerakan sosial keagamaan.

\section{Metode Penelitian}

Penelitian ini menggunakan pendekatan kualitatif yaitu pendekatan penelitian yang berusaha mendeskripsikan suatu gejala, peristiwa, dan kejadian yang terjadi saat ini. ${ }^{33}$ Dalam

\footnotetext{
${ }^{26}$ Rihlah Nur Aulia And Others, 'Pesantren ( Studi Kasus Di Pondok Pesantren Spmaa Lamongan, Jawa Timur ', Xix (2018), 74.

${ }^{27}$ Bakri And M. Ansor Anwar, 'Manajemen Pendidikan Islam Perspektif Kiai Muh . As ' Ad Umar', Jurnal Manajemen Dan Pendidikan Islam, 4.2 (2018), 2.

${ }^{28}$ Feri Andi, 'Peran Majelis Ta'lim Dalam Meningkatkan Pemahaman Keagamaan (Study Terhadap Majlis Ta'limnurul Hidayah Di Desa Taraman Jaya Kecamatan Semendawai Suku Iii Kabupaten Ogan Komering Ulu 'Timur)', 2017. 1.

${ }^{29}$ Khaeriyah Darwis And Andi Rahayu Anwar, 'Pelatihan Olahan Sawi Hijau Untuk Menumbuhkan Jiwa Wirausaha Pada Kelompok Wanita Tani Mt Al Muhajirin Di Kelurahan Tamalanrea Jaya', Jurnal Pengabdian Masyarakat, 1.2 (2018), 67.

${ }^{30}$ Burhanuddin, Ulama Perempuan Indonesia (Jakarta: Pt Gramedia Pustaka Utama, 2002). 6.

31 Abd Karim, 'Pengaruh Majelis Taklim Terhadap Solidaritas Sosial Mekanik Jamaah Majelis Taklim Masjid Al-Barokah, Pengok Kec. Gondokusuman Yogyakarta', 2018. 67.

${ }^{32}$ M. Isnando Tamrin, 'Pendidikan Non Formal Berbasis Masjid Sebagai Bentuk Tanggung Jawab Umat Dalam Perspektif Pendidikan Seumur Hidup’, Menara Ilmu, 7.79 (2018), 77.

33 Chairul Anwar And Others, 'The Effectiveness Of Islamic Religious Education In The Universities: The Effects On The Students' Characters In The Era Of Industry 4.0', Tadris: Jurnal Keguruan
} 
penelitian ini, peneliti akan memberikan gambaran secara kualitatif mengenai peran majelis taklim Al-Hidayah dalam pendidikan islam dan gerakan sosial keagamaan, subjek penelitian ini Pengajian ibu-ibu di Bandar Lampung, Lampung Timur, Lampung Tengah, dan Pesawaran sehingga diperoleh gambaran yang utuh dan menyeluruh dari kiprah, peran, strategi, tindakan dan interaksi anggota komunitas atau organisasi bersangkutan. Sumber data yang digunakan pada penelitian ini meliputi: survey, wawancara, dan studi kepustakaan. Berikut program kerja majelis taklim Al-Hidayah.

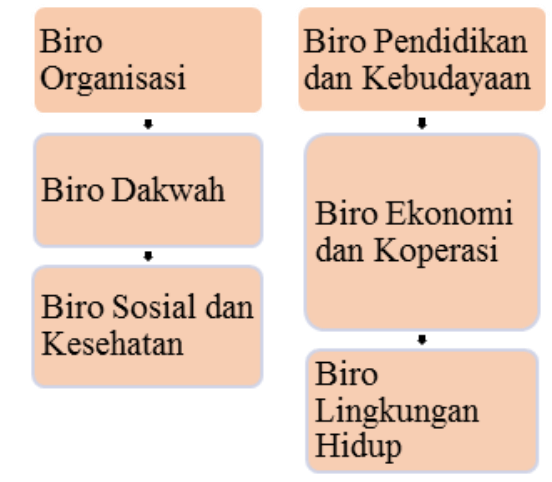

Gambar 1. Program Kerja Majelis Taklim Al-Hidayah

\section{Hasil dan Pembahasan}

\section{Bidang Organisasi}

Majelis taklim Al- Hidayah dalam bidang organisasi melaksanakan konsolidasi pada pengajian-pengajian di Bandar Lampung, Lampung Timur, Lampung Tengah, dan Pesawaran.

\section{Bidang Dakwah}

Majelis taklim Al- Hidayah melakukan pengajaian rutin dengan materi yang bervariasi.

\section{Bidang Sosial dan Kesehatan}

Majelis taklim Al- Hidayah mengadakan seminar mengenai kesehatan reproduksi, kesehatan anak dan mengadakan bakti sosial ke anak yatim dan memberikan bantuan kepada kaum duafa.

\section{Bidang Pendidikan dan Kebudayaan}

Majelis taklim Al- Hidayah membina group kasidah, mendirikan PAUD dan TPA, serta membina guru-guru yang mengajar.

\section{Bidang Ekonomi dan Koperasi}

Majelis taklim Al- Hidayah mengadakan pelatihan tentang ekonomi kreatif, tata rias dan tata boga.

\section{Bidang Lingkungan Hidup}

Majelis taklim Al- Hidayah mengadakan gotong royong dan membuat tanaman TOGA.

Dan Imu Tarbiyah, 3.1 (2018), 78 < Https://Doi.Org/10.24042/Tadris.V3i1.2162>. Lihat juga Akmal Hawi, 'Remaja Pecandu Narkoba: Studi Tentang Rehabilitasi Integratif Di Panti Rehabilitasi Narkoba Pondok Pesantren Ar-Rahman Palembang Abstrak', Tadrib, 4.1 (2018), 101. 
Keberadaan kelompok pengaiian Al-Hidayah diperuntukkan salah satunya sebagai wadah bagi usaha memperkuat pendidikan Islam. Namun pendidikan yang dikenalkan dan diajarkan dalam pengajian Al-Hidayah bersifat non-formal sebagimana sifat Ormas itu sendiri.

Sebagai wadah pendidikan non-formal, tentu saja pendidikan Islam yang dikenalkan dan diajarkan berbeda dengan pendidikan Islam di sekolah formal. Pendidikan yang diajarkan pada kelompok pengajian ini yaitu pendidikan Islam dengan acuan dan landasan al-Qur'an dan Hadits yang disampaikan dalam forum pengajian ibu-ibu. Sebagai nstitusi pendidikan non-formal, pengajian Al-Hidayah telah lama tumbuh dan berkembang di tengah-tengah komunitas muslim pedesaan maupun perkotaan sebagai lembaga dakwah plus pendidikan dan menjadi lembaga yang paling banyak diminati oleh komunitas muslim (terutama kaum perempuan) dalam mengembangkan wawasan keagamaan. Pengajian AlHidayah memiliki visi utama yaitu munculnya kaum perempuan Indonesia yang bertagwa kepada Allah SWT, berakhlak mulia, cerdas, mandiri, dan sejahtera dalam membangun keluarga sakinah, mawaddah warohmah dalam wadah NKRI yang demokratis.

Sedangkan misinya yaitu: (1) Meningkatkan sumber daya perempuan Indonesia melalui aspek keagamaan, pendidikan, kebudayaan dan IPTEK; (2) Menggalang dan menggerakkan kaum perempuan Indonesia beserta seluruh potensi yang dimilikinya; (3) Mengupayakan sistem kehidupan kemasyarakatan, kebangsaan dan kenegaraan yang menjamin hak-hak asasi perempuan dan keluarga; (4) Meningkatkan pemberdayaan kaum perempuan Indonesia di berbagai bidang; (5) Mewujudkan kesetaraan dan keadilan gender dalam berkeluarga dan bermasyarakat. Dalam penelitian Umdatul Hasanah terhadap majelis taklim di Jakarta, keberadaan majelis taklim di Indonesia memang identik dengan kaum perempuan; majelis taklim bukan hanya sebagai lembaga pendidikan keagamaan, namun juga menjadi wadah bagi pengembangan peran publik perempuan, khususnya dalam bidang sosial keagamaan.

Format pendidikan berupa pengajian rutin mingguan dan bulanan yang dikoordinasi oleh masing-masing ketua. Tiap-tiap kabupaten memiliki pengurus sebagai penanggung jawab kegiatan. Materi dan strategi pendidikan pada pengajian Al-Hidayah Lampung mengacu pada sejarah majelis taklim sebagai lembaga pendidikan non-formal. Kalau ditelusuri lebih jauh, kata taklim itu sendiri adalah pengajaran bagi orang-orang yang ingin mendalami ajaran-ajaran Islam. Sebagai sebuah sarana pengajaran agama Islam, kelompok pengajian Al-Hidayah memiliki basis tradisi yang kuat, yaitu mengikuti teladan Nabi Muhammad SAW dalam mensyiarkan agama Islam di awal-awal risalah beliau. Dalam prakteknya, pengajian Al-Hidayah mengacu pada fungsi majelis taklim awal di bidang pendidikan non-formal. Majelis taklim Al-Hidayah merupakan tempat pengajaran atau pendidikan agama Islam yang paling fleksibel dan tidak terikat waktu. Majelis taklim AlHidayah bersifat terbuka terhadap segala usia, lapisan atau strata sosial. Hanya saja, jamaah pengajian semuanya perempuan. Waktu penyelenggaraan pengajian tidak terikat, bisa pagi, siang, sore, ataupun malam hari. Tempat pengajarannya pun bisa dilakukan di rumah, masjid, mushala, kantor, aula, halaman (lapangan) dan sebagainya.

Keberadaan pengajian rutin yang diprakarsai oleh kelompok pengajian Al-Hidayah Lampung inilah yang menjadi kekuatan alternatif atas syiar Islam sehingga eksistensinya 
mampu bertahan dan merupakan lembaga pendidikan Islam yang paling dekat dengan umat (masyarakat), khususnya kaum ibu. Majelis majelis taklim Al-Hidayah Lampung juga merupakan wahana interaksi dan komunikasi yang kuat antara masyarakat dengan para ustadz dan ustadzah, dan antara sesama anggota jamaah majelis taklim.

Dengan demikian, kelompok pengajian Al-Hidayah dapat dikatakan sebagai lembaga pendidikan keagamaan alternatif bagi mereka yang tidak memiliki cukup tenaga, waktu dan kesempatan menimba ilmu agama di jalur pendidikan formal. Inilah yang menjadikan majelis taklim Al-Hidayah memiliki nilai dan karakteristik tersendiri dibanding lembagalembaga pendidikan keagamaan Iainnya.

Mengingat pelaksanaannya yang fleksibel dan terbuka untuk segala waktu dan kondisi, keberadaan majelis taklim Al-Hidayah telah menjadi lembaga pendidikan seumur hidup bagi umat Islam. Oleh karena itu, sangatlah penting untuk memikirkan dan memberdayakan keberadaan majelis taklim Al-Hidayah saat ini dan masa mendatang agar bisa bertahan dan terus berkembang lebih balk, serta menjadi rahmat bagi umat. Untuk itu kami melihat ada dua hal yang perlu menjadi perhatian khusus kita bersama dalam upaya memaksimalkan peran dan fungsi majelis taklim Al-Hidayah, yaitu penataan sistem pengelolaan (manajemen) pendidikan dan penataan sistem kurikulum dan model pembelajaran.

\section{Peran Majelis taklim Al- Hidayah dalam Pendidikan}

Al-Hidayah Lampung aktif bergiat di bidang pendidikan non-formal melalui pengajian ibu-ibu. Selama ini, nama Al-Hidayah lebih dikenal sebagai kelompok atau lembaga pengajian ibu-ibu, karena memang kegiatan utama yang diselenggarakan oleh Al-Hidayah adalah pengajian keislaman. Namun demikian, keberadaan pengajian AlHidayah sejauh pengamatan penulis di tiga kabupaten dan satu kota di propinsi Lampung, kiprah Al-Hidayah tidak semata-mata berperan mensosialisasikan nilai-nilai Islam melalui pengajian atau dakwah, tapi juga aktif melakukan kegiatan sosial, memberdayakan keterampilan kaum perempuan melalui tata rias pengantin dan kegiatan posyandu, pembinaan TPA (Al-Hidayah Lampung Tengah), pendirian lembaga pendidikan anak usia dini (Al-Hidayah Bandar Lampung), pembentukan kasidah dan mawalan (Al-Hidayah Pesawaran), seminar-seminar dengan tema kesehatan reproduksi dan keluarga sejahtera (Al-Hidayah Bandar Lampung), serta peningkatan kualitas da'iyah di empat kabupaten/kota tersebut.

Dari hasil survei dan observasi terhadap empat kelompok pengajian Al-Hidayah di kabupaten Lampung Timur, Lampung Tengah, Pesawaran dan kotamadya Bandar Lampung, Al-Hidayah kini telah memiliki lembaga pendidikan tingkat anak usia dini (PAUD) atau Raudhatul Athfal. Pengajian Al-Hidayah propinsi Lampung juga bergerak dalam pengembangan dan peningkatan kualitas guru TPA di berbagai kabupaten/kota dan propinsi. Ini telah dilakukan dalam rangka memperkuat basis pendidikan Islam non-formal yang diemban oleh pengajian Al-Hidayah.

Hasil wawancara dengan pengurus Al-Hidayah di empat kabupaten di Lampung, diketahui bahwa Al-Hidayah saat ini sedang memfokuskan pada pembenahan kurikulum pendidikan non-formal dan manajemen pendidikan Islam sehingga tertata secara sistematis 
dan terarah. Tujuannya agar pendidikan Islam benar-benar menjadi suatu kegiatan penting dalam pengajian Al-Hidayah di Lampung. Pengembangan pendidikan Islam ini penting karena Al-Hidayah merupakan majelis taklim yang keberadaannya dimaksudkan sebagai wadah memperkuat pendidikan non-formal berbasis ajaran Islam. Kegiatan pendidikan Islam pada pengajian Al-Hidayah tercermin dari beberapa unsur yang telah dilakukan, seperti materi pendidikan semakin bervariasi, tidak hanya menyangkut masalah hukum Islam, tetapi juga materi terkait dengan kesehatan refroduksi perempuan, pemberdayaan kaum perempuan, hak dan kewajiban perempuan dalam rumah tangga, kepemimpinan perempuan.

Kegiatan pendidikan Islam pada pengajian Al-Hidayah tercermin dari beberapa unsur yang telah dilakukan, seperti materi pendidikan semakin bervariasi, tidak hanya menyangkut masalah hukum Islam, tetapi juga materi terkait dengan kesehatan refroduksi perempuan, pemberdayaan kaum perempuan, hak dan kewajiban perempuan dalam rumah tangga, kepemimpinan perempuan. Sementara dalam penyampaian materi digunakan beragam media pembelajaran, baik visul maupun audiovisual, serta menggunakan metode pembelajaran yang beragam seperti ceramah, diskusi, tanya jawab, simulasi atau peragaan. Media yang umum dipergunakan dalam proses pengenalan materi pendidikan pada pengajian Al-Hidayah adalah buku-buku, pengeras suara, alat perekam, dan lainya.

\section{Peran Majelis taklim Al- Hidayah Dalam Gerakan Sosial Keagamaan}

Al-Hidayah juga melaksanakan kegiatan di bidang gerakan sosial keagamaan seperti tanggap atas bencana alam, bakti sosial, pos yandu, seminar tentang kesehatan reproduksi, yang memiliki peran strategis dan penting dalam pengembangan kehidupan beragama kaum perempuan di Lampung. Al-Hidayah Lampung bertujuan untuk mewujudkan learning society, pendidikan kemasyarakatan, di mana targetnya adalah terbentuknya suatu masyarakat yang memiliki wawasan dan kemampuan yang sejajar dengan kaum pria.

Pengajian Al-Hidayah menjadi wahana belajar sekaligus gerakan sosial. Di sini dapat disimpulkan bahwa keberadaan atau eksistensi pengajian Al-Hidayah propinsi Lampung dapat disebuat sebagai lembaga pendidikan keagamaan alternatif bagi kaum perempuan yang tidak memiliki cukup tenaga, waktu dan kesempatan menimba ilmu agama di jalur pendidikan formal. Al-Hidayah menjadi lembaga alternatif untuk kaum perempuan yang hendak belajar dan menimba pengetahuan di masyarakat. Inilah yang menjadikan pengajian Al-Hidayah memiliki nilai dan karakteristik tersendiri bagi ibu-ibu di tiga kabupaten dan satu kota tempat penelitian dilakukan sejak pertengahan 2018, dibandingkan lembagalembaga pendidikan keagamaan lainnya.

Mengingat pelaksanaannya yang fleksibel dan terbuka untuk segala waktu dan kondisi, keberadaan kelompok pengajian Al-Hidayah telah eksis sebagai wadah perkumpulan kaum ibu dalam gerak sosial kemasyarakatan. Pengajian Al-Hidayah merupakan tempat berlangsungnya pendidikan Islam non-formal di Lampung yang membawa misi gerakan sosial keagamaan dengan tujuan agar nilai-nilai Islam terwarisi oleh setiap insan dan mengkarakter dalam dirinya dan direalisasikan dalam prilaku kehidupan sehari-hari oleh umat Islam. 
Nilai-nilai Islam telah melembaga pada masing-masing individu,maka agama ini menjadi tegak didunia, tersebar di seluruh lapisan dunia dan fungsi agama Islam sebagai rahmatanlil 'alamin dapat dibuktikan. Dalam rangka menguatkan pengarusutamaan gender (gender mainstreaming), hasil wawancara penulis dengan empat pengurus Al-Hidayah di kabupaten Lampung Timur, Lampung Tengah, Pesawaran dan Bandar Lampung, menjelaskan bahwa pengajian Al-Hidayah telah berperan aktif mewujudkan kesetaraan dan keadilan gender dalam tubuh organisasi sehingga tercermin dalam kehidupan keluarga dan kemasyarakatan. Keaktifan kaum perempuan dalam majelis taklim menjadi penting mengingat semakin banyak perempuan di Lampung yang memiliki kapasitas kemampuan intelektual dan keagamaan yang ikut dan berkiprah dalam pembangunan, seperti pembangunan sosial-keagamaan.

\section{Catatan Akhir}

Keberadaan pengajian Al-Hidayah propinsi Lampung selama proses penelitian dilakukan sejak pertengahan 2018, menunjukkan peran, tugas dan fungsinya sebagai lembaga pendidikan non-formal yang bergerak pada kelompok perempuan dalam rangka menguatkan kapasitas dan pengetahuan kaum ibu. Dari hasil FGD penulis dengan peserta pengajian Al-Hidayah di Lampung Timur, Lampung Tengah, Pesawaran dan Bandar Lampung, dapat disimpulkan bahwa eksistensi pengajian Al-Hidayah di empat kabupaten/kota di propinsi Lampung itu dapat dikatakan telah menjalankan tugas pokok dan fungsinya sebagai lembaga pendidikan alternatif yang bersifat non-formal dan diminati oleh kaum perempuan sebagai peserta tetap dalam pengajian di bidang pendidikan islam dan gerakan sosial keagamaan.

\section{Daftar Rujukan}

Abdullah, 'Komplementaritas Dakwah Kultural Dan Struktural', Jurnal Pengembangan Masyarakat, 4 (2017), 1-12

Amin, Muliaty, A Marjuni, And Dewi Azharia, 'Gerakan Sosial Keagamaan Masyarakat Perspektif Pendidikan Islam: Majelis Taklim Al-Mu'minat', Jurnal Aqidah-Ta, 4 (2018), 149-59

Anas, Ahmad, And Hendri Hermawan Adinugraha, 'Naqsyabandiyah Di Grobogan', Jurnal Komunikasi Islam, 08 (2018), 180-211

Andi, Feri, 'Peran Majelis Ta'lim Dalam Meningkatkan Pemahaman Keagamaan (Study Terhadap Majlis Ta'limnurul Hidayah Di Desa Taraman Jaya Kecamatan Semendawai Suku Iii Kabupaten Ogan Komering Ulu Timur)', 2017

Anwar, Chairul, Antomi Saregar, Uswatun Hasanah, And Widayanti Widayanti, 'The Effectiveness Of Islamic Religious Education In The Universities: The Effects On The Students' Characters In The Era Of Industry 4.0', Tadris: Jurnal Keguruan Dan Ilmu Tarbiyah, 3 (2018), 77 <Https://Doi.Org/10.24042/Tadris.V3i1.2162>

Ariyani, Farida, Taras Nayana, Antomi Saregar, And Agitha Pricilia, 'Development Of Photonovela With Character Education: As An Alternative Of Physics Learning Media', Jurnal Ilmiah Pendidikan Fisika Al-Biruni, 07 (2018), 227-37 $<$ Https://Doi.Org/10.24042/Jipfalbiruni.V7i2.3072>

Aşlamac1, İbrahim, And Recep Kaymakcan, 'A Model For Islamic Education From Turkey: The Imam-Hatip Schools', 39 (2016), 1-14 
$<$ Https://Doi.Org/10.1080/01416200.2015.1128390>

Aulia, Rihlah Nur, Sari Narulita, Moh Firdaus, And Izzatul Mardhiah, 'Pesantren ( Studi Kasus Di Pondok Pesantren Spmaa Lamongan , Jawa Timur )', Xix (2018), 73-88

Awwaliyah, Robiatul, And Hasan Baharun, 'Pendidikan Islam Dalam Sistem Pendidikan Nasional', Jurnal Ilmiah Didaktika, 19 (2018), 34-49

Aziz, A. Saiful, 'Pendidikan Agama Pada Anak Mucikari Di Lokalisasi Gambilangu Mangkang Semarang', 2016, 1-24

Bakri, And M. Ansor Anwar, 'Manajemen Pendidikan Islam Perspektif Kiai Muh . As' Ad Umar', Jurnal Manajemen Dan Pendidikan Islam, 4 (2018), 1-18

Buer, S, V. Strandhagen, J.O, And F. T. S Chan, 'Industri 4.0 And Lean Manufacturing: Mapping Current Research And Establishing A Research Agenda', International Journal Of Production Research, 56 (2018), 2924-40 <Https://Doi.Org/10.1080/00207543.2018.1442945>

Burhanuddin, Ulama Perempuan Indonesia (Jakarta: Pt Gramedia Pustaka Utama, 2002)

Dahlan, Zaini, 'Kebijakan Pemerintah Orde Baru Terhadap Majelis Ta' Lim', Al-Fatib: Jurnal Pendidikan Dan Keislaman, 1 (2018), 123-52

Darwis, Khaeriyah, And Andi Rahayu Anwar, 'Pelatihan Olahan Sawi Hijau Untuk Menumbuhkan Jiwa Wirausaha Pada Kelompok Wanita Tani Mt Al Muhajirin Di Kelurahan Tamalanrea Jaya', Jurnal Pengabdian Masyarakat, 1 (2018), 67-71

Fajrianty, Handieni, And Ressi Susanti, 'Strategi Pembinaan Dakwah Syarhil Quran Di Padepokan Syarhil Quran Lampung', Jurnal Aqlam, 2 (2017), 129-44

Hawi, Akmal, 'Remaja Pecandu Narkoba: Studi Tentang Rehabilitasi Integratif Di Panti Rehabilitasi Narkoba Pondok Pesantren Ar-Rahman Palembang Abstrak', Tadrib, 4 (2018), 99-119

_ , 'Tantangan Lembaga Pendidikan Islam', Tadrib, 3 (2017), 143-61

Karim, Abd, 'Pengaruh Majelis Taklim Terhadap Solidaritas Sosial Mekanik Jamaah Majelis Taklim Masjid Al-Barokah, Pengok Kec. Gondokusuman Yogyakarta', 2018

Khodijah, Nyayu, 'Majelis Taklim Asy Syifa: Potret Majelis Taklim Dalam Komunitas Muslim Muallaf Di Bali', Ri'ayah, 3 (2018), 74-98

Khoiriyah, Rihlatul, Ali Imron, Ahmad Munif, And Lathifah Munawaroh, 'Penguatan Kampung Santri Untuk Pengembangan Masyarakat Sadar Hukum Di Wilayah Mangkang Kota Semarang', Dimas, 17 (2017), 253-76

Kurniawan, Sugeng, 'Peranan Kepemimpinan Visioner Dalam Manajemen Pendidikan Anak Usia Dini ( Paud )', Nur El-Islam, 5 (2018), 42-62

Kurniawan, Syamsul, 'Pendidikan Karakter Dalam Islam Pemikiran Al-Ghazali Tentang Pendidikan Karakter Anak Berbasis Akhlaq Al-Karimah', Tadrib, 3 (2017), 197-215

Maryam, Siti, 'Pendidikan Agama Islam Dalam Persepektif Al Quran ( Studi Analisis Dalam Memahami Konsep Pendidikan Yang Ada Dalam Al Qur' An )', At-Ta'lim, 5 (2019), 79-96

Marzuki, Ahmad, 'Dinamika Dan Peran Majelis Ta'lim Dalam Meningkatkan Pengetahuan Keagamaan Di Wilayah Suku Tengger', Jurnal Mafhum, 1 (2016), 187-98

Munir, Samsul, 'Politik Pendidikan Islam Berbasis Multikultural: Konsep Dan Strategi Pembelajaran Agama Islam Dalam Mewujudkan Islam Rahmatan Li Al- ' A Lam I N', Dirosat, 2 (2017), 149-82 <Https://Doi.Org/10.28944/Dirosat.V2i2.105>

Mustofa, Muhamad Arif, 'Majelis Ta'lim Sebagai Alternatif Pusat Pendidikan Islam (Studi Kasus Pada Majelis Ta'lim Se Kecamatan Natar Lampung Selatan) Muhamad', Jurnal Kajian Keislaman Dan Kemasyarakatan, 1 (2016), 1-18

Priatmoko, Sigit, 'Memperkuat Eksistensi Pendidikan Islam Di Era 4.0', Ta'lim:Jurnal Studi Pendidikan Islam, 1 (2018), 1-19

Rini Widi Astuti, M Priyatna, Agus Sarifudin, 'Pengaruh Majelis Taklim Ibu-Ibu Terhadap 
Minat Mendalami Agama Islam', Prosiding Al Hidayah Pendidikan Agama Islam, 1 (2018), 138-45

Samsudin, 'Integrasi Tri Pusat Pendidikan Dalam Pendidikan Agama Islam', Al-Murabbi: Jurnal Studi Kependidikan Dan Keislaman, 5 (2019), 216-32

Setiawan, Wahyudi, Fitrah M. Sud, Moh. Toriqul Chaer, And Azam Syukur Rahmatullah, 'Pendidikan Kebahagiaan Dalam Revolusi Industri 4', Al-Murabbi: Jurnal Studi Kependidikan Dan Keislaman, 5 (2018), 101-20

Sukring, Sukring, 'Pendidik Dalam Pengembangan Kecerdasan Peserta Didik (Analisis Perspektif Pendidikan Islam )', Tadris: Jurnal Keguruan Dan Ilmu Tarbiyah, 01 (2016), 69$80<$ Https://Doi.Org/10.1016/J.Aca.2009.07.028>

Suprapto, Agung, 'Analisis Dimensi Kebutuhan Pra Implementasi E-Learning Untuk Meningkatkan Mutu Layanan Pendidikan Kampus Di Era Revolusi Industri 4 . 0', Attarbiyah, 28 (2018), 81-97 <Https://Doi.Org/10.18326/Tarbiyah.V28.81-97>

Tamrin, M. Isnando, 'Pendidikan Non Formal Berbasis Masjid Sebagai Bentuk Tanggung Jawab Umat Dalam Perspektif Pendidikan Seumur Hidup', Menara Ilmu, 7 (2018), 80 93 
